\title{
Deep Western Boundary Current transport variability in the South Atlantic: preliminary results from a pilot array at $34.5^{\circ} \mathrm{S}$
}

\author{
C. S. Meinen ${ }^{1}$, A. R. Piola ${ }^{2}$, R. C. Perez ${ }^{3,1}$, and S. L. Garzoli ${ }^{1}$ \\ ${ }^{1}$ Atlantic Oceanographic and Meteorological Laboratory, Miami, Florida, USA \\ ${ }^{2}$ Servicio de Hidrografía Naval, and Universidad de Buenos Aires, UMI IFAECI/CONICET/CNRS, \\ Buenos Aires, Argentina \\ ${ }^{3}$ Cooperative Institute for Marine and Atmospheric Studies, University of Miami, Miami, Florida, USA
}

Correspondence to: C. S. Meinen (christopher.meinen@noaa.gov)

Received: 13 February 2012 - Published in Ocean Sci. Discuss.: 13 March 2012

Revised: 16 October 2012 - Accepted: 10 November 2012 - Published: 29 November 2012

\begin{abstract}
The first direct estimates of the temporal variability of the absolute transport in the Deep Western Boundary Current (DWBC) at $34.5^{\circ} \mathrm{S}$ in the South Atlantic Ocean are obtained using just under one year of data from a line of four pressure-equipped inverted echo sounders. Hydrographic sections collected in 2009 and 2010 confirm, based on neutral density, temperature, salinity, and oxygen values, the presence of the DWBC, one of the main deep pathways of the Meridional Overturning Circulation. Both data sets indicate that the DWBC reconstitutes itself after breaking into eddies in the western sub-tropical Atlantic near $8^{\circ} \mathrm{S}$. The amplitude and spectral character of the DWBC transport variability are comparable with those observed in the North Atlantic, where longer records exist, with the DWBC at $34.5^{\circ} \mathrm{S}$ exhibiting a transport standard deviation of $25 \mathrm{~Sv}$ and variations of $\sim 40 \mathrm{~Sv}$ occurring within periods as short as a few days. There is little indication of an annual cycle in the DWBC transports, although the observational records are too short to be definitive. A Monte Carlo-style analysis using $27 \mathrm{yr}$ of model output from the same location as the observations indicates that about 48-60 months of data will be required to fully assess the deep transport variability. The model suggests the presence of an annual cycle in DWBC transport, however its statistical significance with even $27 \mathrm{yr}$ of model output is low, suggesting that seasonal variations in the model are weak.
\end{abstract}

\section{Introduction}

The role of the Deep Western Boundary Current (DWBC) as a primary pathway for the cold, lower limb of the meridional overturning circulation (MOC) has been well documented in the North Atlantic Ocean (e.g. Molinari et al., 1998; Schott et al., 2004; Johns et al., 2008; Meinen et al., 2012); however, the pathways and variability of the DWBC in the South Atlantic Ocean are less well known. Near $8^{\circ} \mathrm{S}$ the DWBC appears to break up into rings as it flows southward (Dengler et al., 2004; Schott et al., 2005). It has been suggested that a significant fraction of the DWBC flow transits eastward across the basin in the tropics and/or subtropics and flows southward along the African coast near $30-35^{\circ} \mathrm{S}$ (e.g. Warren and Speer, 1991; Speer et al., 1995; Zangenberg and Siedler, 1998; Van Sebille et al., 2012). Most of this southeastward flow appears to continue along the African coast in the Cape Basin to then enter the Indian Ocean (Speer et al., 1995; Van Aken et al., 2004). There are few observations of the portion of the DWBC that remains along the western boundary south of $8^{\circ} \mathrm{S}$ aside from a small number of sections analyzed using an assumed level of no motion (e.g. Zemba, 1991). The only direct current meter estimates available in the region are from off Cabo Frio $\left(22^{\circ} \mathrm{S}\right)$ and Cabo Santa Marta $\left(28^{\circ} \mathrm{S}\right)$. These 23 -month records indicate a very weak southward volume transport by the DWBC: $-0.5 \pm 1.6$ and $-2.8 \pm 4.9 \mathrm{~Sv}\left(1 \mathrm{~Sv}=10^{6} \mathrm{~m}^{3} \mathrm{~s}^{-1}\right)$, respectively (Müller et al., 1998). The southward geostrophic transport at the western boundary at $28^{\circ} \mathrm{S}$ is estimated at $10 \mathrm{~Sv}$, but about $4 \mathrm{~Sv}$ recirculate northward in the interior (Zangenberg and 


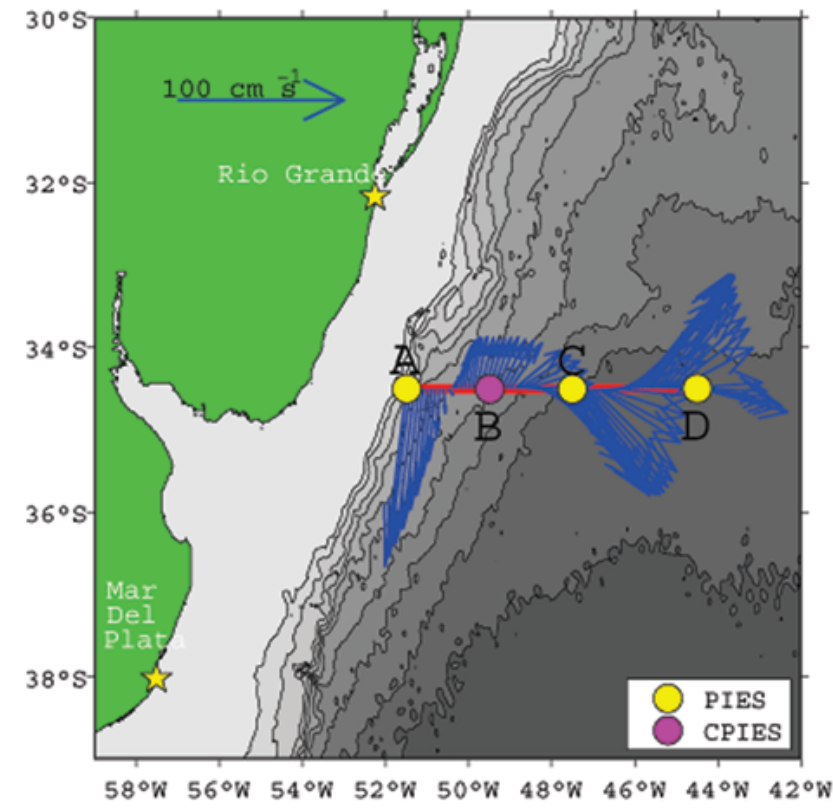

Fig. 1. Map indicating the location of the four PIES/CPIES making up the pilot array. Blue vectors indicate the water velocity at $21 \mathrm{~m}$ measured via shipboard acoustic Doppler current profiler on the Brazilian naval research vessel N. H. Cruzeiro do Sul in March 2009 during the array deployment cruise. Black letters indicate site names - instrument types are noted in legend.

Siedler, 1998). Given the South Atlantic Ocean's role as a "blender"of water masses in the MOC (Garzoli and Matano, 2011), and the indications that the DWBC plays a major role in the meridional heat transport at these latitudes (e.g. Dong et al., 2011), it is important to understand how much of the deep cold limb is transiting the basin and reaching the Southern Ocean over time. The purposes of this article are to describe preliminary results from a pressure-equipped inverted echo sounder (PIES) array deployed across the DWBC at $34.5^{\circ} \mathrm{S}$ on the western boundary of the South Atlantic Ocean north of the Brazil-Malvinas Confluence (typically located near 36-38 S; e.g. Garzoli, 1993) and the Zapiola Eddy (centered near $45^{\circ} \mathrm{S}$; e.g. Fu et al., 2001), and also to demonstrate that the pilot array of PIES is successfully observing the DWBC. The variability observed during the first year of deployment will be compared to $27 \mathrm{yr}$ of output from a high-resolution model to evaluate the statistical information contained in a one-year record.

\section{Data and methods}

In order to monitor the DWBC in the South Atlantic, an array of PIES was designed for deployment in early 2009 (Fig. 1). The location of the array was based on the known circulation features of the western South Atlantic. Specifically, the latitude of the array was selected to be north of the "meandering-window" of the Brazil-Malvinas Confluence while also avoiding a notable topographic "bump" located at about $33.5^{\circ} \mathrm{S}$. Previous studies using inverted echo sounders (e.g. Garzoli, 1993) as well as surface drifter and satellite observations (Olson et al., 1988; Goni et al., 1996; Lentini, 2002; Lumpkin and Garzoli, 2011) have shown that while the Brazil Current does at times displace offshore at $34.5^{\circ} \mathrm{S}$, the Malvinas Current, and hence the Confluence, never reaches north of $36^{\circ} \mathrm{S}$ (e.g. Olson et al., 1988). The array was designed as a purely zonal line for two reasons: first and foremost, the long-term goal of the pilot array project is to build towards a trans-basin array across to South Africa at the same latitude as an existing/planned array off the coast of Africa (see Garzoli et al., 2012 and/or www.aoml.noaa.gov/ phod/SAMOC_international/ for more details of the planned array); and second, having the array aligned zonally allows the meridional variations in the Coriolis parameter to be neglected - which is an advantage in calculating meridional velocities and transports via the geostrophic method.

PIES technology has been in use for several decades, and a large number of previous articles have described the instrument and the data it collects. Only a brief review of the instrument is presented here with appropriate references for more information. In essence, a PIES makes two measurements: the bottom pressure and the round-trip travel time required for a $12 \mathrm{kHz}$ acoustic pulse to travel from the bottommoored instrument up to the sea surface and back. Bottom pressure is measured with a highly precise Paros pressure gauge (e.g. Watts and Kontoyiannis, 1990; Donohue et al., 2010), and the round-trip travel time is determined using a transducer and a high quality crystal clock (e.g. Rossby, 1969; Watts and Rossby, 1977; Tracey and Watts, 1986). The travel time measurements from each PIES $^{1}$ are calibrated into daily, full-water-column profiles of temperature, salinity and specific volume anomaly via hydrography-derived look-up tables using the Gravest Empirical Mode (GEM) technique (e.g. Meinen and Watts, 2000; Watts et al., 2001). The application of the GEM technique to this region in the South Atlantic provides fairly similar signal-to-noise ratio (SNR) accuracies (Fig. 2) to those found in the subtropical North Atlantic, with SNR values of $\sim 20$ in the main thermocline/halocline depth range and ratios decreasing to 1-3 in the deep ocean below 2000 dbar. Note that data availability (gray dotted lines; Fig. 2 middle panel) drops off near the edges and towards the bottom of the GEM field. In these parameter spaces, which tend to be infrequently observed by the PIES, the smoothed GEM field is filled out with interpolation/extrapolation. Future CTD and Argo profiles collected in this region, including the advent of deeper-reaching Argo

\footnotetext{
${ }^{1}$ The travel times estimated from concurrent CTD profiles agree to within $1.5 \mathrm{~ms}$ with the directly measured travel times from the PIES. The observed range in travel times in this region is about $34 \mathrm{~ms}$, so this accuracy represents about $4.4 \%$ of the observed signal.
} 

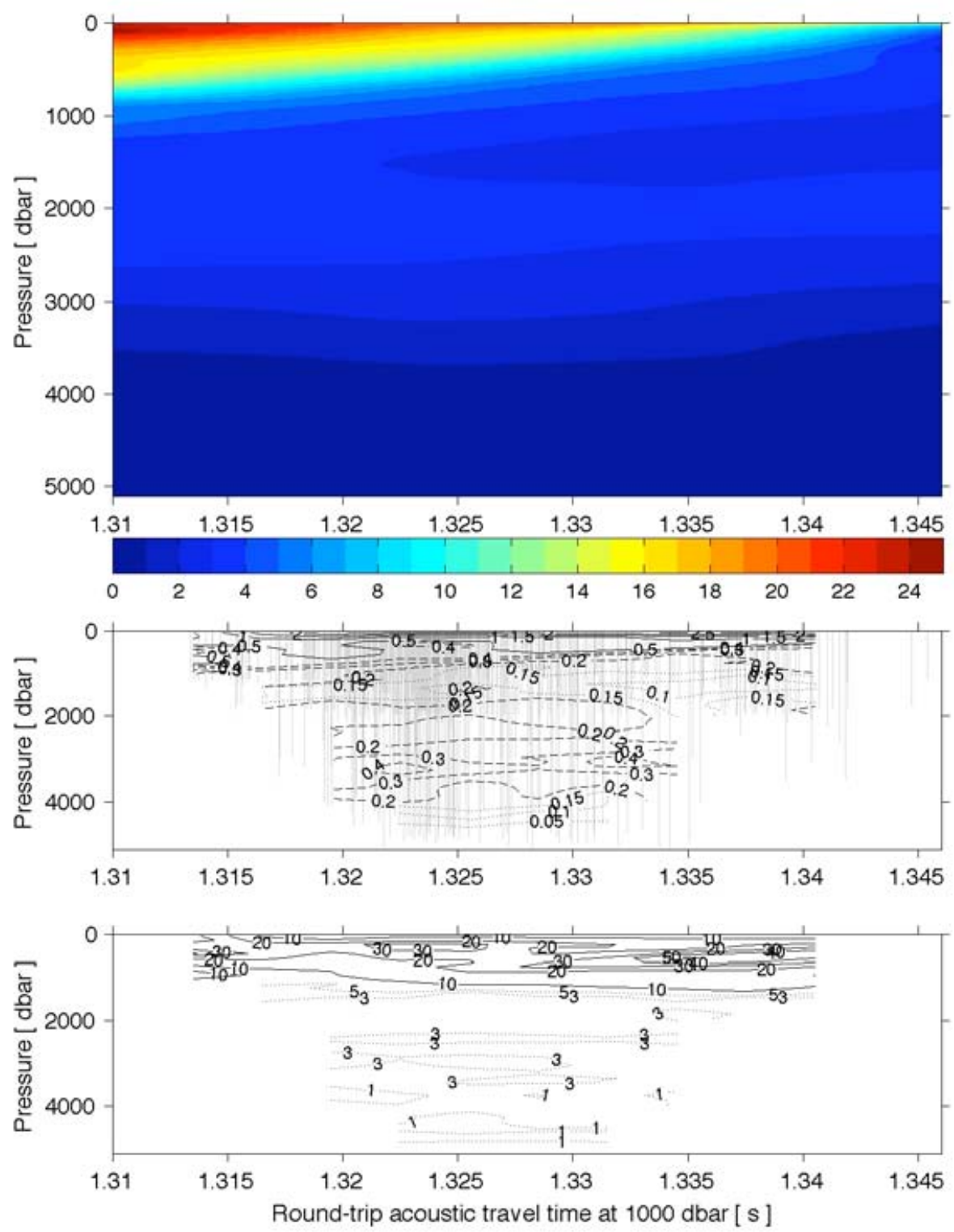

Fig. 2. Upper panel: two-dimensional look-up table of temperature as a function of pressure and simulated travel time between the surface and 1000 dbar created via the GEM method (see text). Middle panel: root-mean-squared (rms) difference between the directly measured CTD or Argo profile temperatures $\left({ }^{\circ} \mathrm{C}\right)$ and the corresponding GEM estimates determined using the GEM field and the simulated travel time determined from the CTD/Argo temperature and salinity profiles. The rms differences are determined in bins of $3 \mathrm{~ms}$ with and $100 \mathrm{dbar}$ height. Gray dotted lines indicate CTD data availability. Lower panel: the rms scatter scaled as a signal-to-noise ratio based on the observed signal at each pressure level.

floats, will allow for ever-improving GEM fields to be created.

Vertically integrating the specific volume anomaly profiles generated from the GEM fields and the travel time measurements yields dynamic height anomaly profiles at the four instrument sites, and differences in dynamic height anomaly profiles between neighboring PIES sites provide relative geostrophic velocity profiles orthogonal to the line between the PIES (e.g. Meinen et al., 2006). Differences in bottom pressure from neighboring PIES sites provide absolute geostrophic velocity variability at the bottom that can be used to reference the relative velocity profiles. Due to the well-known leveling problem $^{2}$, however, the time-mean

\footnotetext{
${ }^{2}$ In brief, a time-mean pressure difference between two neighboring sensors can occur due to the sensors being on the bottom at different depths, or it can occur with two sensors that are at exactly the same depth spanning a time-mean geostrophic current orthogonal to the line between them. With only the two sensors, there is
} 
absolute geostrophic velocity at the bottom cannot be determined from the bottom pressure differences (e.g. Donohue et al., 2010). If an independent estimate of the timemean bottom velocity is available for the region, from historical current meter records, for example, or from concurrent ship-based velocity sections, then this mean can be added to the bottom-pressure-derived time-varying absolute velocities. Unfortunately there are very few, and very sparse, direct observations of the bottom velocity in this region, most of which are concentrated only west of $48^{\circ} \mathrm{W}$ (Garzoli and Baringer, 2007). When independent data are not available, such as is the case for the region at $34.5^{\circ} \mathrm{S}$, the time-mean bottom velocity between pairs of PIES must be derived from another source, such as from a high quality numerical ocean model. The model used in this study for providing the mean bottom velocity will be discussed shortly. Once a time-mean has been added to the time-varying absolute geostrophic velocities determined from the bottom pressure gauges, the resulting absolute velocity time series can be used to reference the relative geostrophic velocity profiles determined from the travel time and GEM look-up tables. The result is full-watercolumn time series of absolute velocity perpendicular to the line between each pair of PIES.

A primary goal of this paper is to discuss the time variability of the DWBC. Defining an integration domain to call the DWBC is somewhat tricky, as the water mass definitions one might use (which will be discussed shortly) in some cases require estimates of dissolved oxygen, which the PIES (as with most moorings) do not provide. For the purposes of this study, therefore, a similar vertical integration domain will be used as was applied in recent work such as at $26.5^{\circ} \mathrm{N}$ (e.g. Meinen et al., 2012); the DWBC transport will be defined as the integral from 800 to $4800 \mathrm{dbar}$ (or the bottom where it is shallower than $4800 \mathrm{dbar}$ ). This allows comparison with the results at other latitudes, and it is consistent with previous work in the region (Garzoli, 1993), which characterized $800 \mathrm{dbar}$ as the lower-bound of the upper layer flows. The character of the transport time series that will be shown is not sensitive to modest, $\pm 100-300$ dbar changes in these integration limits.

The details of the techniques for using PIES to measure the transport of the DWBC have been developed and tested versus other measurement systems in the North At-

insufficient information to discriminate between these two scenarios. This leveling issue relates only to the time-mean, not to the time-varying flow, because the depth difference between two PIES does not change with time (at least within one deployment). Note that this neglects the small density variability in the depth range between the two PIES; a simple estimate using the PIES-GEM records indicates that the deep shear between the depths of Sites A and B (see Fig. 1 for site locations) represents about $4 \%$ of the variance of the full depth dynamic height signal, while the deep shear between Sites B and C represents about $0.3 \%$ of the full depth dynamic height signal. These values are considered small enough to be negligible. lantic at $26.5^{\circ} \mathrm{N}$ (Meinen et al., 2004, 2006, 2012). Most recently, Meinen et al. (2012) showed that PIES-derived absolute transports were accurate as compared to those determined from dynamic height moorings, with a correlation of $r=0.96$, and a root-mean-square difference of $6 \mathrm{~Sv}$, over a roughly equivalent integration domain (correlations for baroclinic transports using an assumed level of no motion at $800 \mathrm{dbar}$ were similarly good). Although there are no independent absolute transport measurements for comparison at $34.5^{\circ} \mathrm{S}$ like there have been at $26.5^{\circ} \mathrm{N}$, the $34.5^{\circ} \mathrm{S}$ GEM signal-to-noise ratios of 20-30 in the main thermocline/halocline depth range and 1-5 at greater depths (see Fig. 2) are similar to those observed at $26.5^{\circ} \mathrm{N}$ and the instrumentation used is identical, suggesting that absolute transport accuracies will be similar for the two arrays.

The PIES data presented here are from a line of four instruments deployed along $34.5^{\circ} \mathrm{S}$ at $51.5^{\circ} \mathrm{W}$ (Site A), $49.5^{\circ} \mathrm{W}$ (Site B), $47.5^{\circ} \mathrm{W}$ (Site C), and $44.5^{\circ} \mathrm{W}$ (Site D) as a pilot array to measure the western boundary components of the MOC (Fig. 1). One instrument was additionally equipped with a single-depth current meter $50 \mathrm{~m}$ above the bottom $(\mathrm{CPIES})^{3}$. Note that the velocity from the current meter cannot be directly compared to the PIES-derived velocities as the latter represent horizontal averages over the span between PIES; thus they represent horizontal averages over $\sim 180$ $275 \mathrm{~km}\left(2-3^{\circ}\right.$ of longitude). As such, the current meter data from only one site are not particularly crucial for the purposes of this paper, although they can be used for model validation. All instruments were deployed in March 2009, and data were acoustically downloaded from the four instruments in July 2010. Due to acoustic transmission issues, the data record from one instrument (Site B: see Fig. 1) is more limited than the others. For this preliminary study, data from the $\sim 10.5$ month period when all four records are available (6 May 2009 to 22 March 2010) will be presented. Data values are at daily resolution, with all records having been lowpass filtered with a cut-off period of three days.

Data from two hydrographic sections completed as part of this pilot study are also presented herein to describe the water masses observed in the region. The sections were occupied during 20-24 August 2009 and 7-11 July 2010. Both cruises were completed on board the Argentine research vessel Puerto Deseado.

\section{Model description}

Detailed absolute velocity observations of the DWBC in the South Atlantic are limited. As such, coupling observational knowledge with high-quality numerical model output presents a useful opportunity to advance understanding

\footnotetext{
${ }^{3}$ The median speed observed by the current meter was about $5 \mathrm{~cm} \mathrm{~s}^{-1}$ with a median direction of about $63^{\circ} \mathrm{T}$. The velocity direction was highly variable, with a somewhat bimodal direction along the local bathymetry.
} 


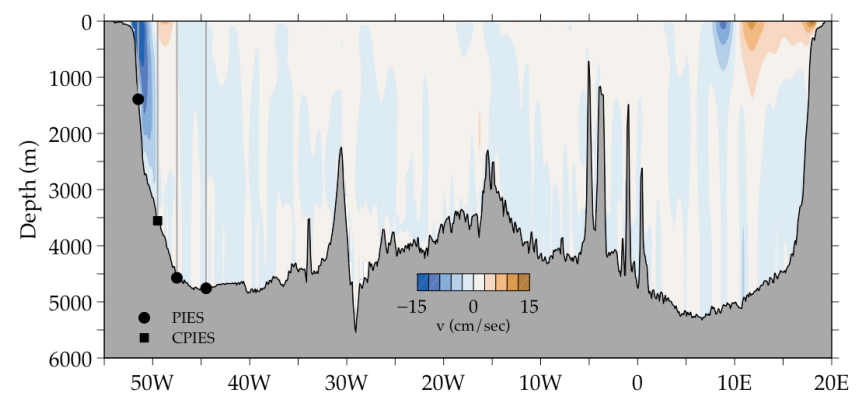

Fig. 3. Contour plot of the OFES model record-length (27-yr) mean meridional velocity, with oranges indicating northward flow and blues indicating southward flow. Also shown are the nominal locations of the PIES/CPIES deployed in the pilot array on the western boundary. Model (OCCAM) 1/10 degree bottom topography is shown in gray.

beyond what either can provide alone. For this study, a numerical model was used for two purposes. First, the model was used to supply the near-bottom time-mean absolute velocity that needs to be combined with the PIES bottompressure-derived time-varying absolute geostrophic velocity anomalies to yield the full near-bottom absolute geostrophic velocity. Second, the model was used to obtain an estimate of the statistical stability of the deep flows from short records relative to longer-period variations.

The model product selected for this study is from a run of the Ocean general circulation model For the Earth Simulator (OFES; e.g. Sasaki et al., 2008). The OFES model is a massively parallelized implementation of the National Oceanic and Atmospheric Administration/Geophysical Fluid Dynamics Laboratory (NOAA/GFDL) Modular Ocean Model version 3 (MOM3) being executed by the Japan Agency for Marine-Earth Science and Technology (JAMSTEC). The model equations have been discretized in a Mercator B-grid with a horizontal resolution of $0.1^{\circ}$ and 54 vertical $z$ levels. For this study, model fields were provided by JAMSTEC at $0.2^{\circ}$ increments (every other horizontal grid point) at 3-day increments (snapshots, not 3-day averages) over the period from 1980 to 2006 . The model was spun up for 50-yr with a monthly climatology derived from $\mathrm{Na}-$ tional Centers for Environmental Prediction/National Center for Atmospheric Research (NCEP/NCAR) reanalysis atmospheric fluxes (Masumoto et al., 2004), and then forced with daily mean NCEP/NCAR reanalysis data from 1950 to 2006 (Sasaki et al., 2008). Only the data from the final $27 \mathrm{yr}$ of the run were used herein. This model has previously been successfully validated against both other models and the limited available observations in the South Atlantic (Perez et al., 2011; Dong et al., 2011; E. Giarolla, personal communication, 2010).

To obtain the time-mean absolute velocity near the bottom for use with the actual bottom pressure measurements, the velocities from the model were first temporally averaged
Table 1. Time-mean near-bottom meridional velocity from the OFES model averaged over the horizontal span between the indicated pairs of PIES/CPIES and over the deepest three layers (common to both sites) above the model ocean bottom. Negative velocity indicates southward flow. Also shown are the real ocean depths at each of the actual PIES/CPIES sites and the model ocean depths at the nearest model grid points.

\begin{tabular}{lrrr}
\hline Site/Span & Mean velocity & $\begin{array}{r}\text { Real } \\
\text { ocean depth }\end{array}$ & $\begin{array}{r}\text { Model } \\
\text { ocean depth }\end{array}$ \\
\hline Site A & $1360 \mathrm{~m}$ & $1429 \mathrm{~m}$ \\
$\begin{array}{l}\text { Span from A-to-B } \\
\text { Site B }\end{array}$ & $-5.8 \mathrm{~cm} \mathrm{~s}^{-1}$ & $3535 \mathrm{~m}$ & $3831 \mathrm{~m}$ \\
$\begin{array}{l}\text { Span from B-to-C } \\
\text { Site C }\end{array}$ & $-0.1 \mathrm{~cm} \mathrm{~s}^{-1}$ & & \\
Span from C-to-D & $+0.2 \mathrm{~cm} \mathrm{~s}^{-1}$ & $4540 \mathrm{~m}$ & $4760 \mathrm{~m}$ \\
Site D & & $4757 \mathrm{~m}$ & $4760 \mathrm{~m}$ \\
\hline
\end{tabular}

over the full $27 \mathrm{yr}$ of the model run, and then these time-mean velocities were horizontally averaged between the longitudes of the pilot array moorings. The mean meridional velocities from the model are shown in Fig. 3 along with the nominal locations of the PIES/CPIES discussed in this article. The mean velocity of the three deepest model layers common to both sites was then averaged in order to obtain the mean reference velocity (the results are not particularly sensitive to different selections of the deepest levels - differences are less than $0.2 \mathrm{~cm} \mathrm{~s}^{-1}$ ). This provides a "best estimate" for the geostrophic time-mean absolute velocity at the bottom between each pair of moorings ${ }^{4}$.

To obtain transports from the model, the model velocities were integrated between the nearest grid points to the four pilot array sites for comparison to the observed data. Note that transport integration domains in the model are not exactly the same as in the real ocean because the model topography is not identical to the real ocean topography. The mean bottom velocities from the model as well as the model and real ocean depths at the four sites are shown in Table 1.

\section{Results}

In this region the precise offshore location, zonal extent, and variability of the DWBC are not as well known as in some other regions due to the paucity of velocity observations. However, the presence of the DWBC is clearly evident from hydrographic observations such as temperature, salinity, dissolved oxygen and nutrient sections (e.g. Reid et al., 1977; Zemba, 1991; Piola and Matano, 2001). The

\footnotetext{
${ }^{4}$ The time-mean meridional velocity from the CPIES at Site B over the 10.5-month time period discussed in the paper is about $1.60 \mathrm{~cm} \mathrm{~s}^{-1}$, while the time-mean meridional velocity from OFES at the grid point nearest to Site B over the $27-y r$ of the output used in the paper in the model is $1.62 \mathrm{~cm} \mathrm{~s}^{-1}$ - so the model velocities agree very well with the limited direct velocity measurements available.
} 
higher-than-ambient dissolved oxygen signal at $\sim 2500 \mathrm{dbar}$ clearly indicates more recently ventilated waters, although as indicated in the July 2010 section (Fig. 4) the signal is not always as tightly confined along the boundary as might be expected for the DWBC. The selection of the A, B, C and $\mathrm{D}$ sites for the pilot array (Fig. 1) was designed based on previous hydrographic and IES observations to capture the DWBC flow and allows for offshore meanders/shifts as far as $44.5^{\circ} \mathrm{W}$. Overlaying the neutral density surfaces, calculated following Jackett and McDougall (1997), can help identify water masses being carried meridionally across the array. Based on an analysis of deep water masses in the northwest Argentine Basin, Preu et al. (2012) proposed the following water mass boundaries/definitions:

- Antarctic Intermediate Water (AAIW): salinity less than $34.25 \mathrm{psu}$;

- Upper Circumpolar Deep Water (UCDW): neutral density between 27.75 and 27.90 with dissolved oxygen values below $4.5 \mathrm{mLL}^{-1}$;

- North Atlantic Deep Water (NADW): neutral density between 27.90 and 28.10 with salinity greater than $34.8 \mathrm{psu}$;

- Lower Circumpolar Deep Water (LCDW): neutral density between 28.06 and 28.20 with salinity less than $34.8 \mathrm{psu}$;

- Antarctic Bottom Water (AABW): potential temperature less than $0^{\circ} \mathrm{C}$.

Based on these definitions, the deep oxygen maximum observed in July 2010 in Fig. 4 is identifiable as NADW. The oxygen section also clearly depicts a relative minimum $<5 \mathrm{~mL} \mathrm{~L}^{-1}$ ) below the core of NADW, associated with LCDW, and a near bottom increase to $>5.1 \mathrm{~mL} \mathrm{~L}^{-1}$ at depths greater than $4000 \mathrm{dbar}$, indicative of AABW. Temperature and salinity sections from this cruise (not shown) are consistent with the presence of AAIW, NADW, and AABW.

In August 2009 another CTD section was collected along the mooring line over the course of five days (20-24 August 2009). The potential temperature and salinity sections indicate the presence of AAIW, NADW, and AABW along the section with no clear indication of LCDW (not shown). Unfortunately, the oxygen data from this cruise are problematic due to a sensor malfunction; thus, UCDW in this section can only be identified based on neutral density. The strong preponderance of NADW between the 27.90 to 28.10 neutral surface layers suggests that within the domain of the section the bulk of the $800-4800$ dbar waters at the time of this section were of North Atlantic origins.

Comparing the mean potential temperature, salinity and specific volume anomaly profiles estimated from the PIES data averaged over the five days of the August 2009 CTD section (Fig. 5, blue lines) to the actual CTD profile data

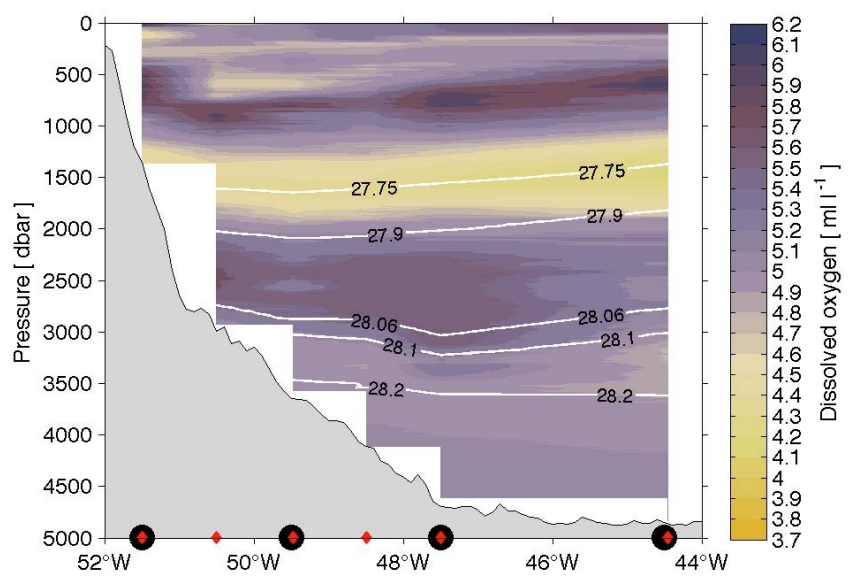

Fig. 4. Dissolved oxygen section collected along the PIES/CPIES line during 7-11 July 2010 on the Argentine research vessel Puerto Deseado. Red diamonds along bottom axis indicate locations of the CTD profiles, and black dots indicate the PIES/CPIES sites. White contours with labels indicate neutral density surfaces. Bottom topography from the Smith-Sandwell dataset (Smith and Sandwell, 1997 ) is shown in gray.

(Fig. 5, red lines) illustrates how well the PIES can estimate the general water mass patterns and the layer interfaces. In general there is very good agreement. In the upper 100-200 dbar there are differences related to the reduced seasonal signal that comes from the application of the GEM technique to PIES data. These differences can be reduced in the future through the application of a "seasonal GEM correction" (Watts et al., 2001). The seasonal differences have no significant impact on the velocities, however, as the latter are based on horizontal density gradients and not the density at any given point. Below the seasonally-affected layer, the agreement through the main thermocline/halocline layer is excellent, while at depths below 2000 dbar there are some more noticeable differences. Note in particular the larger differences from the comparison at Site C below 2000 dbar; the lack of error bars on the PIES-GEM profile indicates that for the observed travel time measurement, there was little or no CTD data available for building the GEM field and estimating its accuracy in that parameter space (see Fig. 2, middle panel). The CTD profile at site C presents an anomalously thick NADW layer, characterized by anomalously high potential temperature and salinity in the $\sim 2500-3500 \mathrm{~m}$ depth range that is not captured by the GEM profile. Fortunately there is compensation between the temperature and salinity anomalies, and the resulting error in specific volume anomaly is small (Fig. 5, bottom panel). While future inclusion of more data in building the GEM fields will improve the fidelity of the look-up tables, some small fluctuations at depth are probably beyond the capability of the PIES-GEM technique to capture. These fluctuations have been shown to have little or no impact on the volume transports (e.g. Meinen et al., 2004), but they do have great importance with regards 

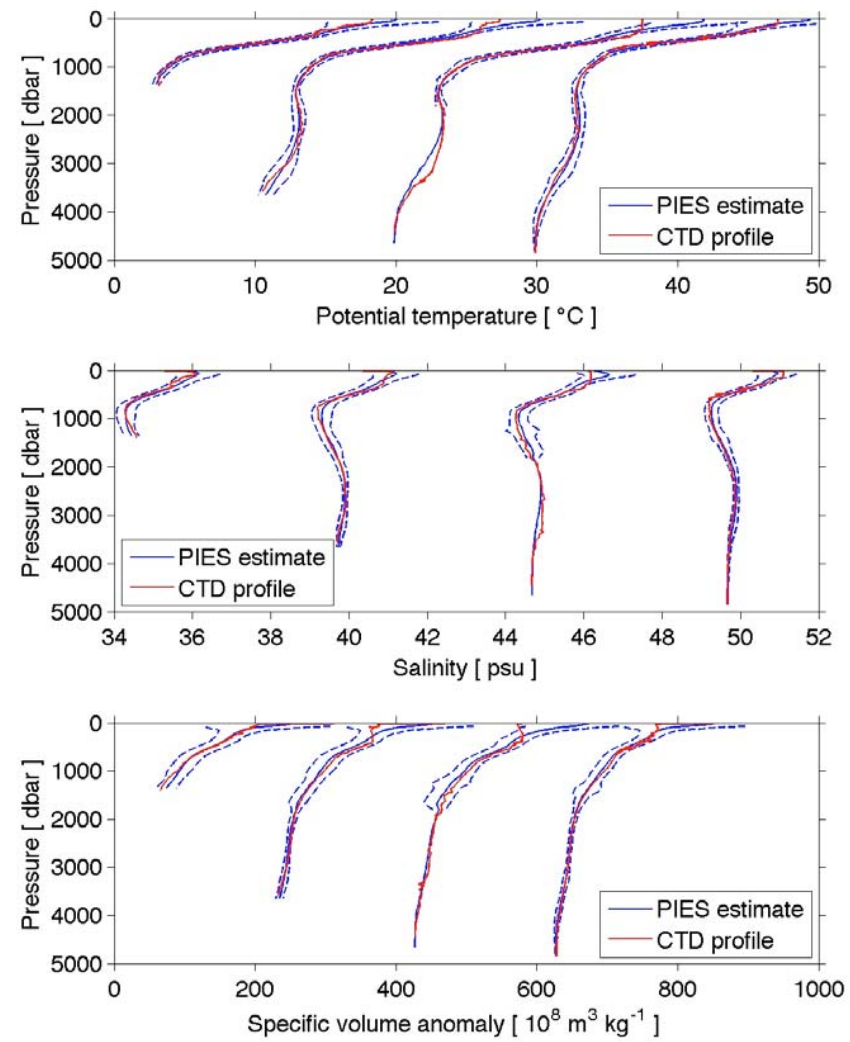

Fig. 5. Comparison of CTD profiles of potential temperature (upper panel), salinity (middle panel) and specific volume anomaly (lower panel) collected at the four PIES/CPIES sites during the 2024 August 2009 cruise to the PIES-GEM estimated profiles averaged over the same five days. Profiles were offset by $10^{\circ} \mathrm{C}, 5 \mathrm{psu}$ and $200 \times 0^{8} \mathrm{~m}^{3} \mathrm{~kg}^{-1}$, respectively, to facilitate viewing; profiles are illustrated from west to east (Sites A to D) across the array moving from left to right in the figure. Conductivity measurements by the CTD were noisy due to a sensor problem; the data have been smoothed vertically to remove small artificial vertical structures. CTD data are shown as red solid lines, while PIES estimates are blue solid lines. Blue dashed lines represent $95 \%$ confidence estimates around the GEM profiles based on the observed scatter of the hydrographic data used to create the GEM fields.

to understanding the source regions of the water masses (e.g. Molinari et al., 1998; van Sebille et al., 2011).

\subsection{Absolute velocity and transport}

The time-mean and the temporal standard deviation of the absolute velocity profiles (Fig. 6) indicate large variability throughout the array during the first 10.5 months of the experiment, with the standard deviation generally exceeding the mean. The strong, highly varying flow in the upper water column on the western side of the array is associated with the Brazil Current, which is thought to be confined above $\sim 800$ dbar (e.g. Garzoli and Garraffo, 1989), while the upper water column flow on the east side is likely associated
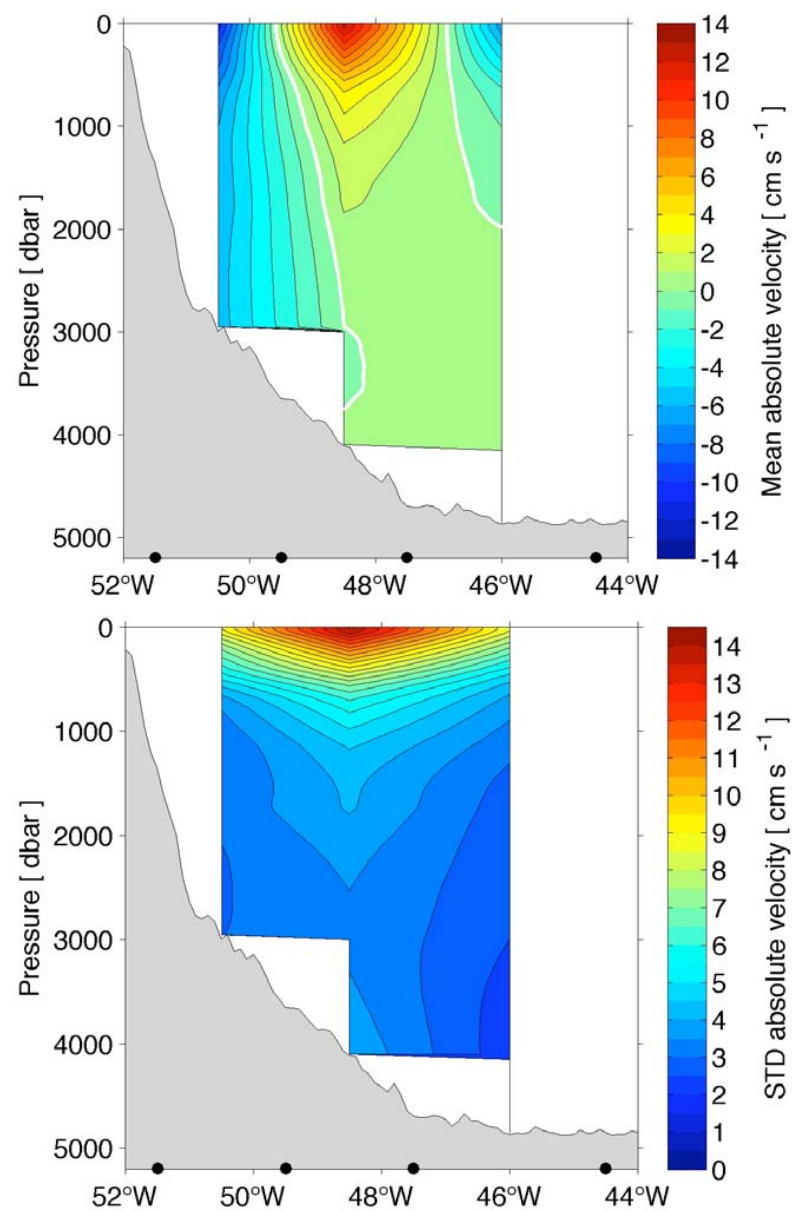

Fig. 6. Upper panel: time-mean absolute meridional velocity determined between pairs of PIES/CPIES along the array. Lower panel: standard deviation of the time-varying absolute meridional velocity determined between the pairs of PIES/CPIES along the array. Black dots along lower axis denote locations of the PIES/CPIES.

with the meandering of retroflected waters coming from the Brazil-Malvinas Confluence to the south (e.g. see velocity vectors in Fig. 1). The estimated near surface velocities $\left(\sim 15 \mathrm{~cm} \mathrm{~s}^{-1}\right)$ from the PIES are significantly lower than the $35 \pm 14 \mathrm{~cm} \mathrm{~s}^{-1}$ mean surface velocity estimated from surface drifters at this location (Oliveira et al., 2009). This is most likely due to two factors: the broad smoothing which results from calculating geostrophic velocity over the 2 $3^{\circ}$ longitudinal spans between PIES; and possibly also due to the drifter velocities including the Ekman flow, which is absent from the PIES transports. Below 800 dbar there is still significant mean flow and variability on the western side of the array, which is associated with the DWBC based on the aforementioned water mass evaluation as well as historical hydrographic observations in the region (e.g. Zemba, 1991). The time-mean DWBC was found to be strongest between Sites A and B immediately beneath the southward flowing Brazil Current (note that part of the Brazil Current, and a 
small portion of the DWBC, are missed west of Site A). The statistical standard error of the mean ranges from $\sim 1 \mathrm{~cm} \mathrm{~s}^{-1}$ below $2000 \mathrm{dbar}$ to roughly $4 \mathrm{~cm} \mathrm{~s}^{-1}$ in the upper $500 \mathrm{dbar}$ between Sites B and C, which suggests that the mean pattern is fairly robust except below $\sim 1500 \mathrm{dbar}$ further offshore between Sites B-C and C-D. However, the mean profiles are highly dependent on the OFES model time-mean bottom velocities used, so the focus of this analysis is on the time variability. Offshore in the upper water column, the mean flow reversal and high variability suggests the presence of strong anti-cyclonic circulations most likely associated with the retroflection of the Brazil Current just to the south at the Brazil-Malvinas Confluence (e.g. Olson et al., 1988; Garzoli and Garraffo, 1989). This retroflection appears to be much tighter than was suggested in some earlier studies (Peterson and Stramma, 1991; Stramma and England, 1999), but it resembles the circulation pattern of satellite-derived mean dynamic topography (Rio and Hernandez, 2004) and the OFES numerical simulation (Fig. 3) ${ }^{5}$. At the DWBC depths (below $800 \mathrm{dbar}$ ) the strongest velocity variability is between Sites B and $\mathrm{C}$.

These results expressed as velocities might be somewhat deceptive in the sense that they represent horizontal averages over the distance between sites, and those distances are not all the same. The span between Sites C and D is $50 \%$ larger than the spans between the other pairs of instruments. As such, it is also instructive to focus on transports integrated between pairs of sites, as the transport integration eliminates this issue. Integrating the absolute transport between each pair of sites and between 800 and $4800 \mathrm{dbar}$ (or the bottom where it is shallower than $4800 \mathrm{dbar}$ ) indicates that the deep flow is quite variable in all three spans (Fig. 7). The standard deviations of the daily time series ${ }^{6}$ are 12,27 and $28 \mathrm{~Sv}$ for the A-to-B, B-to-C and C-to-D spans, respectively. This indicates that the transport variability is equally high offshore in the C-to-D span as it is in the B-to-C span nearer the slope. The variability in the A-to-B span is significantly weaker than that in the B-to-C span. If the observed time variability is based primarily on zonal movement of quasistable velocity signals, e.g. the meandering of a fairly stable DWBC, then moving the velocity signal across integration domains of significantly different size will result in transport amplitude fluctuations of different magnitudes, and the difference in amplitudes between the A-to-B and B-to-C spans is roughly consistent with the smaller integration domain of the A-to-B span in the deep layer due to the sloping topography (see Fig. 4).

The transport within each span shows variability on time scales ranging from a week to a month or two, and each ex-

\footnotetext{
${ }^{5}$ Recall that only the deepest levels (common to adjacent sites) in the model were used to add to the measured bottom pressure gradients, so the shallower levels are independent.

${ }^{6}$ Recall that the PIES records have been low-pass filtered with a 3-day cutoff.
}

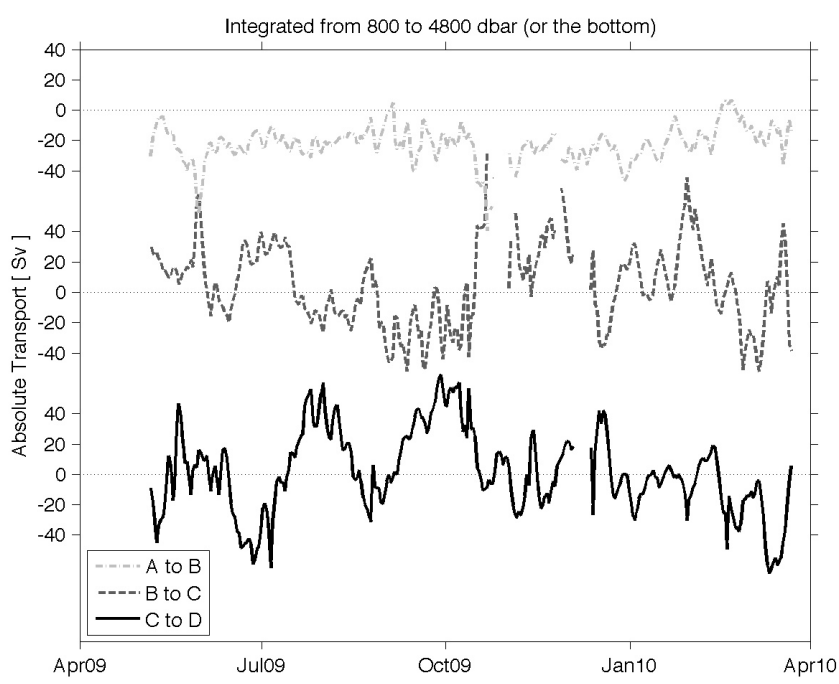

Fig. 7. Absolute transport integrated within the DWBC layer (800$4800 \mathrm{dbar}$ ) and between the indicated pairs of PIES/CPIES (see Fig. 1 for locations). Standard deviations of the three records are 12,27 , and $28 \mathrm{~Sv}$ for the A-to-B, B-to-C and C-to-D spans, respectively.

hibits transport changes exceeding $40 \mathrm{~Sv}$ on extremely fast time scales (Fig. 7). If the strong signals represented just a meandering of the DWBC from one span to another (for example, from being located primarily between Sites B and C to being located primarily between Sites $C$ and D), then the transports should show similar amplitude but out-of-phase signals. While there are certain events that suggest anticorrelation between the more highly variable offshore B-to-C and C-to-D time series (e.g. the southward transport maximum in the B-to-C span in December 2009 and the corresponding northward transport maximum in the C-to-D span), those time series are not correlated with one another in a statistically significant way $(r=-0.38)$. The two more inshore spans, A-to-B and B-to-C, are significantly anti-correlated at the $95 \%$ level $(r=-0.53)$. Note that this significant evaluation is based on the estimated integral time scale of 910 days for the three records (calculated via the methods described in Emery and Thomson, 1997) and the requirement for two integral time scales per degree of freedom based on the lag integration limits (see Appendix B in Meinen et al., 2009 for more information). Despite its significance, the anti-correlation between the A-to-B and B-to-C deep transports is quite modest, and a linear relationship between the two would only explain $\sim 25 \%$ of the observed variance. This lack of strong correlation in the presence of very high amplitude variations is similar to that observed at $26.5^{\circ} \mathrm{N}$ (e.g. Meinen et al., 2012), and it illustrates the importance of integrating over a fairly large domain in order to average out small-scale features that are likely not related to overall DWBC variations. 
Integrating over the complete array from Sites A to D in the deep layer (800-4800 dbar) yields a transport that varies from a northward maximum of $+46 \mathrm{~Sv}$ to a southward maximum of $-83 \mathrm{~Sv}$, with variations exceeding $40 \mathrm{~Sv}$ over very short time scales ( $\sim 1$ week) and a standard deviation of $25 \mathrm{~Sv}$ (Fig. 8). Note that the mean southward transport of $-17 \mathrm{~Sv}$ is dependent on the mean bottom velocities used from OFES, and as such the focus here is on the transport variability. The standard deviation of the transport in the subtropical South Atlantic at $34.5^{\circ} \mathrm{S}$ integrating $\sim 7^{\circ}$ of longitude offshore is roughly comparable with that found with over $5 \mathrm{yr}$ of data from an array of PIES stretching $\sim 5^{\circ}$ of longitude offshore in the subtropical North Atlantic at $26.5^{\circ} \mathrm{N}$ (16 Sv, see Meinen et al., 2012; note also that the first year of PIES data at $26.5^{\circ} \mathrm{N}$ found a mean of $23 \mathrm{~Sv}$, see Meinen et al., 2004). The observed standard deviation at $34.5^{\circ} \mathrm{S}$ exceeds by about a factor of two that observed at "Line W" at $\sim 39^{\circ} \mathrm{N}(12.5 \mathrm{~Sv}$; Toole et al., 2011); however while the vertical integration limits applied at Line $\mathrm{W}$ are roughly similar to those used here, the horizontal integration domain used in this study is about $250 \%$ larger than that used at Line W. Notwithstanding the difference in horizontal integration domains, the roughly similar level of variability observed at these three latitudes suggests that the DWBC domains exhibit similar degrees of high frequency "noise" at three locations where the DWBC has recently reattached to the boundary after flowing into the interior at the Grand Banks, where the DWBC is thought to be fairly consistently located along the continental slope, and where the DWBC has reattached after breaking into rings/eddies at the eastern tip of Brazil (i.e. at Line $\mathrm{W}$, at $26.5^{\circ} \mathrm{N}$, and at $34.5^{\circ} \mathrm{S}$, respectively). This similar degree of variability suggests that much of this higher frequency variability is likely due to similar dynamics propagating into the domains from the east - most likely Rossby waves - although the short length of the record at $34.5^{\circ} \mathrm{S}$ makes attribution of the observed signals difficult at this time. Propagating waves have been observed south of the pilot array, at the Confluence (Garzoli and Simionato, 1990). These earlier IES observations support the existence of two upper layer waves that propagate at different periods in the 30 to 40 days range in opposite direction. The westward propagating wave is forced by the presence of the front while the eastward propagating wave resembles a topographic Rossby wave forced by the meandering of the current. However, the nature of the variability at $34.5^{\circ} \mathrm{S}$, upstream from the BrazilMalvinas Confluence, may be distinct from that observed further south.

Perhaps the most interesting result from this analysis of the pilot array data becomes evident when the absolute transport (black solid line in Fig. 8) is compared to the baroclinic transport relative to an assumed level of no motion (cf. at 800 dbar; dark gray dashed line in Fig. 8). These two time series are completely uncorrelated with one another $(r=-0.23)$, and at times can disagree by as much as 50 100 Sv (e.g. early December 2009, and early March 2010).

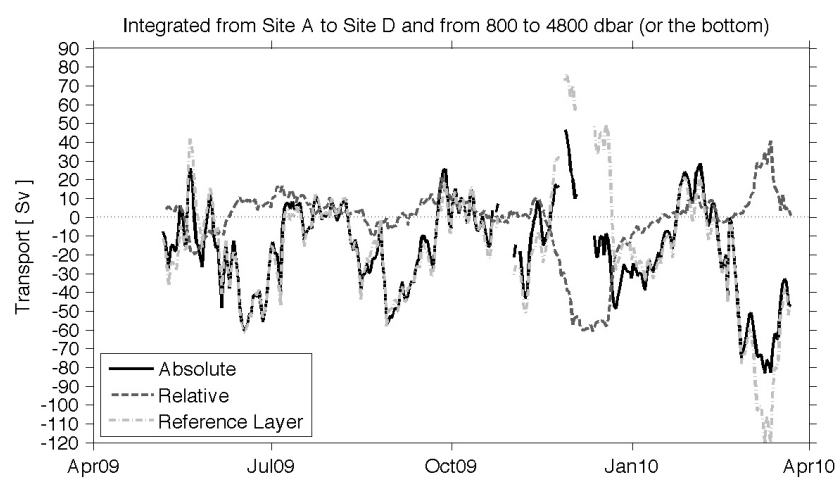

Fig. 8. Absolute transport (black line) integrated between Sites A and D within the nominal DWBC layer (800-4800 dbar). Also shown are the components of the absolute transport associated with velocity relative to an assumed level of no motion at $800 \mathrm{dbar}$ (dark gray dashed) and with the absolute velocity actually observed at the level of no motion reference layer (light gray dash-dot).

This strongly illustrates the point raised previously in analyses of XBT data and numerical model output (e.g. Baringer and Garzoli, 2007; Garzoli and Baringer, 2007) that the barotropic flows are strong and need to be measured to study the absolute flow near the western boundary near $34.5^{\circ} \mathrm{S}$. If the transport associated with the true velocity at the assumed level of no motion is integrated over the DWBC domain (light gray dash-dot line in Fig. 8), it has a significantly higher standard deviation ( $32 \mathrm{~Sv}$ ) than that of the true absolute transport $(25 \mathrm{~Sv})$ or the baroclinic transport $(18 \mathrm{~Sv})$.

Independent validation of the absolute velocity and transport data is difficult as there are no other in situ observations at this latitude; however, the hydrographic observations (e.g. Fig. 4) suggest that the absolute velocity section (Fig. 6) is quite realistic:

1. The low oxygen water above the NADW, associated with UCDW, is lower at the easternmost station $\left(4.18 \mathrm{~mL} \mathrm{~L}^{-1}\right.$ at $\left.1400 \mathrm{dbar}\right)$, where the flow is northward, than on the boundary $\left(\sim 4.42 \mathrm{mLL}^{-1}\right.$ at $\sim 1365$ dbar) where the flow is southward. Thus, the westernmost UCDW core is recirculating southward along the boundary and increasing its $\mathrm{O}_{2}$ concentration by vertical mixing.

2. The high oxygen $\left(>5.76 \mathrm{mLL}^{-1}\right)$ NADW core at $\sim 2500$ dbar close to the boundary is part of the southward flowing DWBC, while the offshore $\sim 2400$ 2800 dbar core (oxygen $>5.68 \mathrm{~mL} \mathrm{~L}^{-1}$ ) located near $47^{\circ} \mathrm{W}$ is part of the northward recirculation (Figs. 4 and $6)$. These cores are separated by a low oxygen region $\left(<5.30 \mathrm{~mL} \mathrm{~L}^{-1}\right)$. This is further confirmed by the salinity distribution, as the bulk of the high salinity deep water $(>34.94 \mathrm{psu})$ is only observed in the westernmost station. 

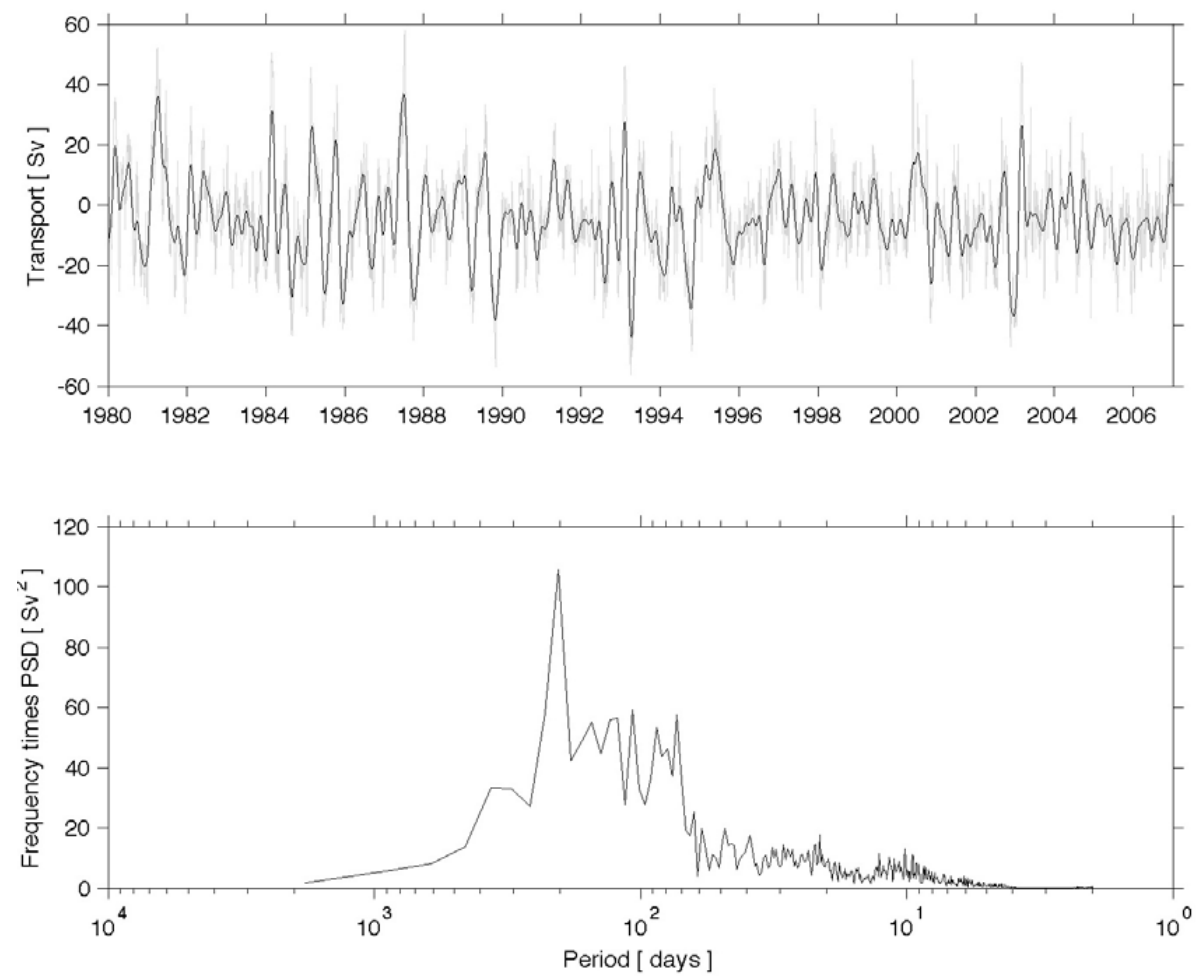

Fig. 9. Upper panel: DWBC transport from the OFES model integrated over the same span as the real observations. Gray line is the 3-day subsampled model output, while the black line is the 90-day low-pass filtered record. Lower panel: spectra of the DWBC transport from OFES (using the 3-day subsampled, unfiltered data).

3. The lowest oxygen $\left(<4.80 \mathrm{mLL}^{-1}\right)$ observed below the NADW core, associated with LCDW, is found at $\sim 3000-3500$ dbar at the easternmost station (Fig. 4) where the mean flow is weakly northward, while it increases to $\sim 4.93 \mathrm{mLL}^{-1}$ at the slope (Fig. 6).

4. Finally, the high oxygen bottom core, associated with AABW, is located mostly east of $49^{\circ} \mathrm{W}$, and is therefore in the region of northward flow below the recirculated NADW.

The baroclinic component of the transport (relative to an assumed level of no motion at $800 \mathrm{dbar}$ ) from the PIES can be compared to that estimated from the August 2009 CTD section; the concurrent PIES transport $(-7 \mathrm{~Sv})$ is stronger and southward, whereas the CTD section estimate $(+3 \mathrm{~Sv})$ is weaker and to the north; however, given the expected large errors due to the non-synoptic nature of the hydrographic section (having needed 5 days to complete; see the variability in Fig. 8), this level of agreement is perhaps promising. Thus, to the extent that the hydrographic observations made on these cruises are representative of the mean over the first year of the study, the mean velocity section (utilizing the deep OFES means) is consistent with the hydrographic information.

\section{Discussion}

At this early stage of analysis of the pilot array, the most important results are likely to come from a joint analysis of the data with the output from a high-quality, high-resolution general circulation model such as OFES. The standard deviation of transport integrated over the same domain within the 3-day subsampled model output over the full $27 \mathrm{yr}$ of the run used herein is $16 \mathrm{~Sv}$ (Fig. 9, upper panel). This is only about two-thirds the standard deviation of the observed absolute transports, however the time period is quite different (10.5 months of data versus $27 \mathrm{yr}$ of model output). A simple Monte Carlo-style test using 1000 random 10.5 month subsets of the $27 \mathrm{yr}$ model record suggests that a record of 10.5 months length in the model could have standard deviations between 8 and $24 \mathrm{~Sv}$, with the mean and median standard deviations of records of that length being 14 and $13 \mathrm{~Sv}$, respectively. Because the largest standard deviation for a 10.5 month record in the model $(24 \mathrm{~Sv})$ is roughly equal to that of the observed data from the pilot array $(25 \mathrm{~Sv})$, it cannot be definitively stated that the variability of the model is too low; however, it seems likely that the model is underestimating the true transport variability since the true data only overlaps with one extreme end of the model range.

While the comparison of the short data records to the much longer OFES transports suggests the latter may be 
underestimating the true amplitude of the variability, it is still potentially instructive to evaluate the spectrum of the long model run to evaluate character of the variability that might be expected to be observed once the pilot array records are longer (Fig. 9, lower panel). Using a 5-yr window for the spectral calculations, the largest energy peak is at a period of about 202 days, close to the semiannual period, and there is a much lower, much broader peak close to the annual period. An annual climatology of the OFES transport record (Fig. 10) suggests a weak ( $\pm 5 \mathrm{~Sv})$ annual cycle with the maximum southward transport in late October (austral spring) and maxima in northward transport in February and May-June (austral summer and late austral fall). The scatter of the daily values is quite high; however, this small annual cycle compared to other shorter-term variability is (barely) statistically significant from zero at the $95 \%$ confidence level (dashed lines in Fig. 10). There is no obvious indication of a significant semiannual or annual period to the observed record (Fig. 8), but, given the large higher frequency variability with only just under one year of data from the pilot array, it is premature to draw a conclusion with regards to the presence or lack of an annual cycle in the DWBC transports at this latitude. An analysis of the DWBC transports at $26.5^{\circ} \mathrm{N}$ using a 5-yr record illustrated no statistically significant annual or semiannual cycle at that location; however, the calculation was somewhat dependent on the distance integrated offshore (Meinen et al., 2012). When integrated over a smaller domain nearer the shelf, a stronger annual cycle appears at $26.5^{\circ} \mathrm{N}$ during 2004-2009. However, based on the observed scatter at that location, even this stronger annual cycle at $26.5^{\circ} \mathrm{N}$ is not statistically significant from zero. Several years of additional data will be required to evaluate whether a significant annual cycle exists in the real ocean at $34.5^{\circ} \mathrm{S}$.

The long model record can also be used to determine the length of record needed to encapsulate the bulk of the expected variability at $34.5^{\circ} \mathrm{S}$ (at least to the extent that the model spectra reproduces the real ocean spectrum; comparison of the model spectrum and data spectrum from the pilot array, not shown, finds significant differences at periods of less than 100 days). A similar 1000-sample Monte Carlostyle calculation was made, examining the variance of 1,10 , $18,36,60$ and 120-month subsets as compared to the variance of the full 27-yr model record (Fig. 11). Not surprisingly, as the record length of the Monte Carlo-style subsample increases, the observed variance asymptotes to the fullrecord variance of $232 \mathrm{~Sv}^{2}$ for the full $27-\mathrm{yr}$ record (see the black solid line converging to the horizontal dotted line in Fig. 11). The full range of the 1000 subsamples (gray filled area in Fig. 11) and the standard deviation of the estimated variances (red cross-hatched area in Fig. 11) become smaller with increasing subsample record length. Assuming the spectral distribution of energy in the model closely approximates that of the real ocean, this suggests that 48-60 months of data will be required before the observed variance would approx-

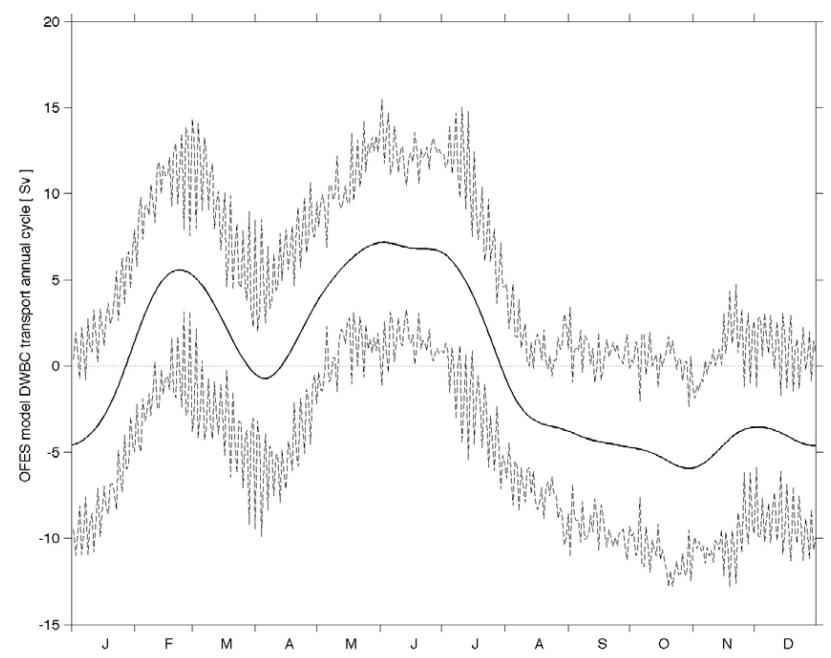

Fig. 10. Annual cycle of the DWBC transport calculated from the 27 yr of OFES model output. Annual cycle was determined as a daily climatology that was smoothed with a 60-day 2nd order Butterworth low pass filter. Dashed lines indicate plus and minus two standard errors (95\% confidence limits).

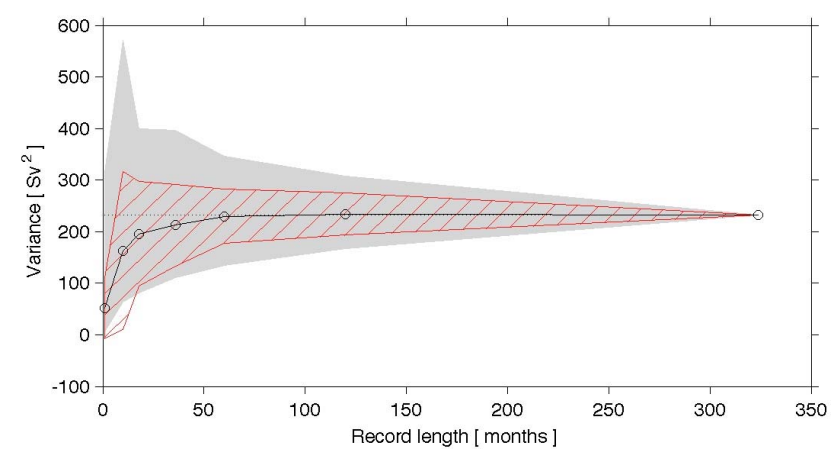

Fig. 11. Median DWBC transport variance determined via a Monte Carlo-style calculation using 1000 random selections of the indicated record lengths of the OFES time series shown in Fig. 8. Complete record variance is shown as the right-most point and the horizontal dotted line. Gray region illustrates the maximum and minimum range observed for all random subsamples of a given record length, while the red cross-hatched area indicates the median values plus and minus one standard deviation of the subsample variances.

imate that of a longer-term (i.e. decadal to multi-decadal) record. Given the potential disagreement between the model and real ocean variability that is hinted at by the amplitude difference between model and reality, and the lack of any obvious suggestion of annual or semi-annual energy in the first 10.5 months of data, it is likely that this $4-5 \mathrm{yr}$ requirement is a lower bound for the required record length. 


\section{Conclusions}

Just under a year of data from a pilot array of pressureequipped inverted echo sounder (PIES) moorings have been used to provide a first glimpse at the time-varying absolute flow of the Deep Western Boundary Current (DWBC) at $34.5^{\circ} \mathrm{S}$. The 10.5 months of PIES data illustrate a high degree of DWBC variability in this short time span, with a transport standard deviation of $25 \mathrm{~Sv}$ when integrated from $800-4800 \mathrm{dbar}$ (or the bottom) and from 51.5 to $44.5^{\circ} \mathrm{W}$. This high transport variability is comparable to that found in the subtropical gyre in the North Atlantic at $26.5^{\circ} \mathrm{N}$, which is somewhat surprising given the deep circulation pattern believed to exist in the South Atlantic at $34.5^{\circ} \mathrm{S}$ where a significant fraction of the signal is expected to be on the eastern boundary (e.g. Warren and Speer, 1991; Speer et al., 1995; van Sebille et al., 2012). It is clear that the variability of the DWBC must be studied in the context of other features that exist in the basin. The observed velocity variability is surface intensified (see the lower panel of Fig. 6) rather than bottom trapped, which suggests planetary Rossby waves rather than topographic Rossby waves, but the relatively short record and limited number of events observed to date make specific identification of the mechanisms behind the observed variability difficult at this early stage in the program.

Ultimately, the goal of this pilot array is to build, with international collaborative projects, a trans-basin monitoring array for the meridional overturning circulation (MOC) along $34.5^{\circ} \mathrm{S}$. The limited nature of historical/independent observations of the absolute deep transports at $34.5^{\circ} \mathrm{S}$ (e.g. Zenk et al., 1999) makes validation at this location difficult; however, the technique has been carefully validated at other locations and comparison with a concurrent hydrographic section and to output from a high-quality, high-resolution, ocean general circulation model at $34.5^{\circ} \mathrm{S}$ gives some measure of confidence in these preliminary results. Future augmentation with additional moored instruments (e.g. Perez et al., 2011), longer time series at these existing sites, and use of global Lagrangian and/or satellite observations (e.g. Lumpkin and Garzoli, 2011) will lead to better understanding of the DWBC variability at this location, and ultimately of the relationship between DWBC variability with that of the basin-wide MOC.

Acknowledgements. The authors would like to express their great appreciation to the crews and officers of the Argentine and Brazilian vessels who have supported this program to date, on board the Brazilian naval research vessel N. H. Cruzeiro do Sul and the Argentine research vessel A. R. A. Puerto Deseado (CONICET). Also, our sincere thanks to the scientific participants who have collected the PIES/CPIES data during the cruises: Rigoberto Garcia, Ulises Rivero, Pedro Peña, and Aldo Firpo. And our thanks to those who have helped coordinate these challenging international cruise collaborations, especially Ariel Troisi and Raul Guerrero in Argentina and Edmo Campos in Brazil. The two hydrographic sections presented herein were collected with support from the Argentine Servicio de Hidrografía Naval, the University of Buenos Aires, and the US NOAA. Finally, many thanks to the generous researchers who provided us with the OFES model output, especially Yoshikazu Sasai at JAMSTEC, and Ricardo Matano at OSU. Rick Lumpkin, Claudia Schmid and two anonymous reviewers provided helpful suggestions for improving this manuscript, and their help is gratefully acknowledged. ARP acknowledges the support of grant CRN2076 from the Inter-American Institute for Global Change Research, which is supported by the US National Science Foundation (GEO-0452325). CSM, RCP and SLG also acknowledge support from the NOAA Atlantic Oceanographic and Meteorological Laboratory and the NOAA Climate Program Office.

Edited by: M. Hecht

\section{References}

Baringer, M. O. and Garzoli, S. L.: Meridional heat transport determined with expendable bathythermographs, Part I, Deep-Sea Res. I, 54, 1390-1401, 2007.

Dengler, M., Schott, F. A., Eden, C., Brandt, P.,Fischer, J., and Zantopp, R.: Break-up of the Atlantic Deep Western Boundary Current into eddies at $8^{\circ} \mathrm{S}$, Nature, 432, 1018-1020, 2004.

Dong, S., Garzoli, S. L., and Baringer, M. O.: The role of interocean exchanges on decadal variations of the northward heat transport in the South Atlantic, J. Phys. Oceanogr., 41, 1498$1511,2011$.

Donohue, K. D., Watts, D. R., Tracey, K. L., Greene, A. D. and Kennelly, M.: Mapping circulation in the Kuroshio Extension with an array of current and pressure recording inverted echo sounders, J. Atmos. Oceanic Tech., 27, 507-527, doi:10.1175/2009JTECHO686.1, 2010.

Emery, W. J. and Thomson, R. E.: Data analysis methods in Physical Oceanography, Elsevier, New York, 634 pp., 1997.

Fu, L.-L., Cheng, B., and Qiu, B.: 25-day period large-scale oscillations in the Argentine Basin revealed by the TOPEX/Poseidon altimeter, J. Phys. Oceanogr., 31, 506-517, 2001.

Garzoli, S. L.: Geostrophic velocity and transport variability in the Brazil-Malvinas Confluence, Deep-Sea Res. I., 40, 1379-1403, 1993.

Garzoli, S. L. and Baringer, M. O.: Meridional heat transport determined with expendable bathythermographs, Part II, Deep-Sea Res. I, 54, 1402-1420, 2007.

Garzoli, S. L. and Garraffo, Z.: Transports, Frontal motions and eddies at the Brazil-Malvinas Currents Confluence, Deep-Sea Res., 36, 681-703, 1989.

Garzoli, S. L. and Matano, R. P.: The South Atlantic and the Atlantic meridional overturning circulation, Deep-Sea Res. II, 58, 18371847, 2011.

Garzoli, S. and Simionato, C.: Barotropic Instabilities and Forced Oscillations in the Brazil/Malvinas Confluence Front., Deep-Sea Res., 37, 1053-1074, 1990.

Garzoli, S., Abrahamsen, P., Ansorge, I., Biastoch, A., Campos, E., Mata, M., Meinen, C., Pelegri, J., Perez, R., Piola, A., Reason, C., Roberts, M., Speich, S., Sprintall, J., Watts, R., and all of the SAMOC IV participants:, South Atlantic Meridional Overturning Circulation (SAMOC) - Fourth Workshop, CLIVAR Exchanges, 58, 2-4, 2012. 
Goni, G., Kamholz, S., Garzoli, S., and Olson, D.: Dynamics of the Brazil-Malvinas Confluence based on inverted echo sounders and altimetry, J. Geophys. Res., 101, 16273-16289, 1996.

Jackett, D. and McDougall, T.: A neutral density variable for the World's Oceans', J. Phys. Oceanogr., 27, 237-263, 1997.

Johns, W. E., Beal, L. M., O. Baringer, M., Molina, J. R.,. Cunningham, S. A, Kanzow, T., and Rayner, D.: Variability of shallow and deep western boundary currents off the Bahamas during 2004-2005: Results from the $26^{\circ} \mathrm{N}$ RAPID - MOC array, J. Phys. Oceanogr., 38, 605-623, doi:10.1175/2007JPO3791.1, 2008.

Lentini, C. A. D.: The role of the Brazil-Malvinas Confluence on regional mesoscale dynamics and climate, Ph.D. Thesis, University of Miami, 192 pp., 2002.

Lumpkin, R. and Garzoli, S.: Interannual to decadal changes in the western South Atlantic's surface circulation, J. Geophys. Res., 116, C01014, doi:10.1029/2010JC006285, 2011.

Masumoto, Y., Sasaki, H., Kagimoto, T., Komori, N., Ishida, A., Sasai, Y., Miyama, T., Motoi, T., Mitsudera, H., Takahashi, K., Sakuma, H., and Yamagata, T.: A fifty-year eddy-resolving simulation of the World Ocean - Preliminary outcomes of OFES (OGCM for the Earth Simulator), J. Earth Simulator, 1, 35-56, 2004.

Meinen, C. S. and Watts, D. R.: Vertical structure and transport on a Transect across the North Atlantic Current near $42^{\circ} \mathrm{N}$ : Time series and mean, J. Geophys. Res., 105, 21869-21892, 2000.

Meinen, C. S., Garzoli, S. L., Johns, W. E., and Baringer, M. O.: Transport variability of the Deep Western Boundary Current and the Antilles Current off Abaco Island, Bahamas, Deep-Sea Res. I, 51, 1397-1415, 2004.

Meinen, C. S., Baringer, M. O., and Garzoli, S. L.: Variability in Deep Western Boundary Current transports: Preliminary results from $26.5^{\circ} \mathrm{N}$ in the Atlantic, Geophys. Res. Lett., 33, L17610, doi:10.1029/2006GL026965, 2006.

Meinen, C. S., Luther, D. S., and Baringer, M. O.: Structure, transport and potential vorticity of the Gulf Stream at $68^{\circ} \mathrm{W}$ : Revisiting older data sets with new techniques, Deep-Sea Res. I, 56, 41-60, 2009.

Meinen, C. S., Johns, W. E., Garzoli, S. L., van Sebille, E., Rayner, D., Kanzow, T., and Baringer, M. O.: Variability of the Deep Western Boundary Current at $26.5^{\circ} \mathrm{N}$ during 2004-2009, DeepSea Res. II, in press, doi:10.1016/j.dsr2.2012.07.036, 2012.

Molinari, R. L., Fine, R. A., Wilson, W. D., Curry, R. G., Abell, J., and McCartney, M. S.: The arrival of recently formed Labrador Sea Water in the Deep Western Boundary Current at $26.5^{\circ} \mathrm{N}$, Geophys. Res. Lett., 25, 2249-2252, 1998.

Müller, T. J., Ikeda, Y., Zangenberg, N., and Nonato, L. V.: Direct measurements of western boundary currents off Brazil between 20 and $28^{\circ}$ S, J. Geophys Res., 103, 5429-5437, 1998.

Oliveira, L. R., Piola, A. R., Mata, M. M., and Soares, I. D.: Brazil Current surface circulation and energetics observed from drifting buoys, J. Geophys. Res., 114, C10006, doi:10.1029/2008JC004900, 2009.

Olson, D. B., Podestá, G. P., Evans, R. H., and Brown, O. B.: Temporal variations in the separation of Brazil and Malvinas Currents, Deep-Sea Res., 35, 1971-1990, 1988.

Perez, R. C., Garzoli, S. L., Meinen, C. S., and Matano, R. P.: Geostrophic velocity measurement techniques for the meridional overturning circulation and meridional heat transport in the South Atlantic, J. Atmos. Ocean. Tech., 28, 1504-1521, doi:10.1175/JTECH-D-11-00058.1, 2011.

Peterson, R. G. and Stramma, L.: Upper-level circulation in the South Atlantic Ocean, Prog. Oceanogr., 26, 1-73, doi:doi:10.1016/0079-6611(91)90006-8, 1991.

Piola, A. R. and Matano, R. P.: Brazil and Falklands (Malvinas) Currents, in: Encyclopedia of Ocean Sciences, Vol. 1, edited by: Steele, J. H., Thorpe, S. A., and Turekian, K. K., London, Academic Press, UK, 340-349, doi:10.1006/rwos.2001.0358, 2001.

Preu, B., Hernández-Molina, F. J., Violante, R., Piola, A., Paterlini, C. M., Schwenk, T., Voigt, I., Krastel, S., and Spiess, V.: Morpho-sedimentary characteristics of the northern Argentine margin: The interplay between erosive, depositional and gravitational processes, Deep-Sea Res. I, submitted, 2012.

Reid, J. L., Nowlin, W. D., and Patzert, W. C.: On the characteristics and circulation of the Southwestern Atlantic Ocean, J. Phys. Oceanogr., 7, 62-91, 1977.

Rio, M.-H. and Hernandez, F.: A mean dynamic topography computed over the world ocean from altimetry, in situ measurements, and a geoid model, J. Geophys. Res., 109, C12032, doi:10.1029/2003JC002226, 2004.

Rossby, T.: On monitoring depth variations of the main thermocline acoustically, J. Geophys. Res., 74, 5542-5546, 1969.

Sasaki, H., Nonaka, M., Sasai, Y., Uehara, H., and Sakuma, H.: An eddy-resolving hindcast simulation of the quasiglobal ocean from 1950 to 2003 on the Earth Simulator, in "High Resolution Numerical Modelling of the Atmosphere and Ocean", edited by: Hamilton, K. and Ohfuchi, W., Springer, New York, 157-185, 2008.

Schott, F. A., Zantopp, R., Stramma, L., Dengler, M., Fischer, J., and Wibaux, M.: Circulation and deep-water export at the western exit of the Subpolar North Atlantic, J. Phys. Oceanogr., 34, 817-843, 2004.

Schott, F. A., Dengler, M., Zantopp, R., Stramma, L., Fischer, J., and Brandt, P.: The Shallow and deep western boundary circulation of the South Atlantic at $5-11^{\circ} \mathrm{S}$, J. Phys. Oceanogr., 35, 2031-2053, 2005.

Smith, W. H. F. and Sandwell, D. T.: Global sea floor topography from satellite altimetry and ship depth soundings, Science, 277, 1956-1962, 1997.

Speer, K. G., Siedler, G., and Talley, L.: The Namib Col Current, Deep-Sea Res., 42, 1933-1950, 1995.

Stramma, L. and England, M.: On the water masses and mean circulation of the South Atlantic Ocean, J. Geophys. Res., 104, 20863-20883, doi:10.1029/1999JC900139, 1999.

Toole, J. M., Curry, R. G., Joyce T. M., McCartney, M., and Peña-Molino, B.: Transport of the North Atlantic Deep Western Boundary Current at about $39^{\circ} \mathrm{N}, 70^{\circ} \mathrm{W}, 2004-2008$, Deep-Sea Res. II, 58, 1768-1780, 2011.

Tracey, K. L. and Watts, D. R.: On Gulf Steam meander characteristics near Cape Hatteras, J. Geophys. Res., 91, 7587-7602, 1986.

Van Aken, H. M., Ridderinkhof, H., and de Ruister, W. P. M.: North Atlantic deep water in the south-western Indian Ocean, Deep-Sea Res. I, 51, 755-776, 2004.

Van Sebille, E., Baringer, M. O., Johns, W. E., Meinen, C. S., Beal, L. M., de Jong, M. F., and van Aken, H. M.: Propagation pathways of classical Labrador Sea Water from its source region to $26^{\circ} \mathrm{N}$, J. Geophys. Res., 116, C12027, 
doi:10.1029/2011JC007171, 2011.

Van Sebille, E., Johns, W. E., and Beal, L. M.: Does the vorticity flux from Agulhas rings control the zonal pathway of NADW across the South Atlantic?, J. Geophys Res., 117, C05037, doi:10.1029/2011JC007684, 2012.

Warren, B. A. and Speer, K. G.: Deep circulation in the eastern South Atlantic Ocean, Deep-Sea Res., 38, 281-322, 1991.

Watts, D. R. and Kontoyiannis, H.: Deep-ocean bottom pressure measurement: Drift Removal and performance, J. Atmos. Oceanic Technol., 7, 296-306, 1990.

Watts, D. R. and Rossby, H. T.: Measuring dynamic heights with inverted echo sounders: Results from MODE, J. Phys. Oceanogr., 7, 345-358, 1977.
Watts, D. R., Sun, C., and Rintoul, S.: A two-dimensional Gravest Empirical Mode determined from hydrographic observations in the Subantarctic Front, J. Phys. Oceanogr., 31, 2186-2209, 2001.

Zangenberg N. and Siedler, G.: The path of the North Atlantic Deep Water in the Brazil Basin, J . Geophys Res., 103, 5419-5428, 1998.

Zemba, J. C.: The structure and transport of the Brazil Current between 27 and $36^{\circ} \mathrm{S}$, Doctoral dissertation, Woods Hole Oceanographic Institution, 146 pp., 1991.

Zenk, W., Siedler, G., Lenz, B., and Hogg, N. G.: Antarctic Bottom Water flow through Hunter Channel, J. Phys. Oceanogr., 29, 2785-2801, 1999. 